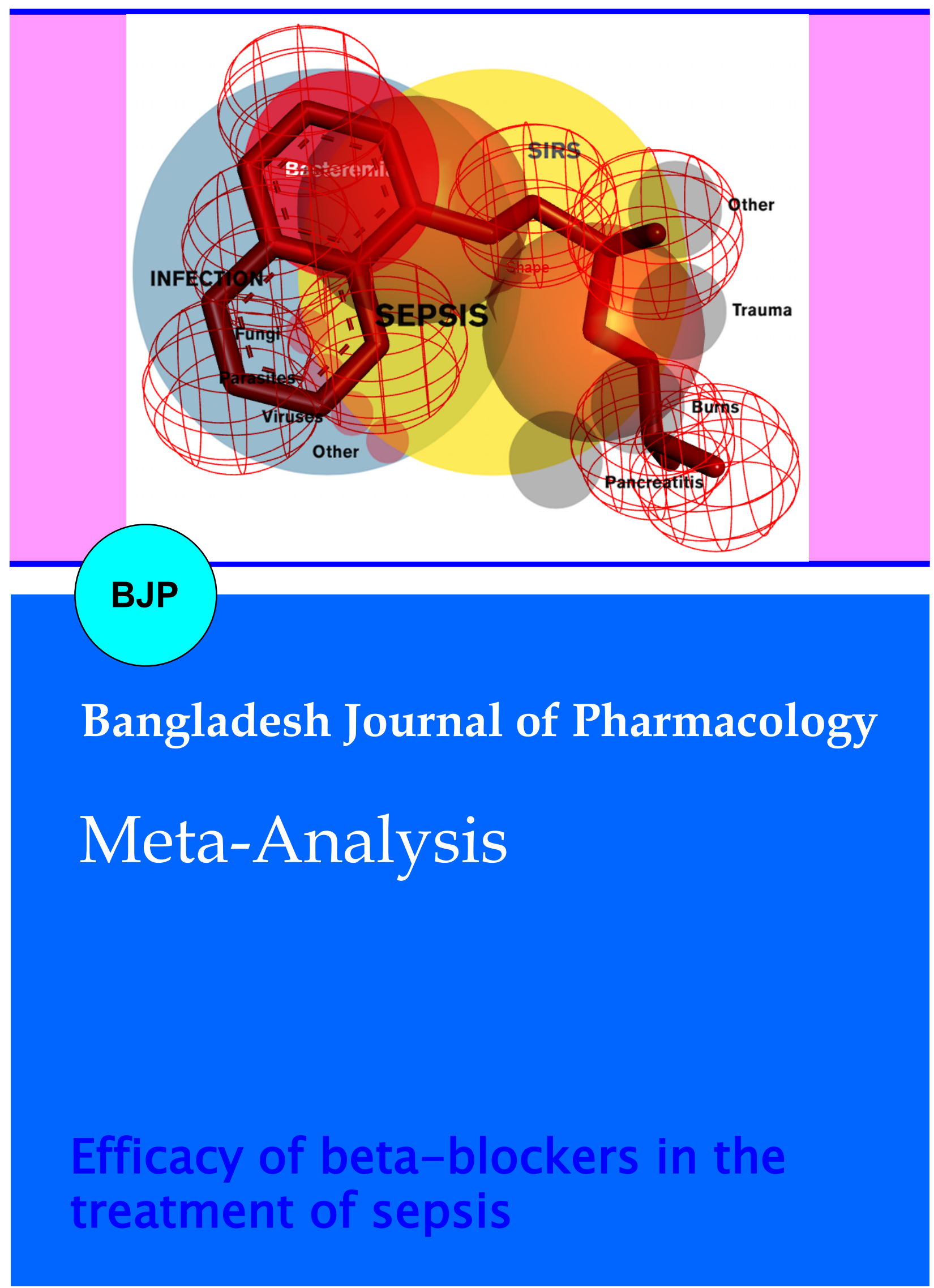




\title{
Efficacy of beta-blockers in the treatment of sepsis
}

\author{
Peng Jin', Tao Zhao', Yueyue Wei' ${ }^{1}$ and Fang Zhao
}

${ }^{1}$ Department of Critical Care Medicine, Hangzhou Fuyang Hospital of Traditional Chinese Medicine, Hangzhou, China; ${ }^{2}$ Department of Emergency Intensive Care Unit, Zhuji Affiliated Hospital of Shaoxing University, Shaoxing, China.

\begin{tabular}{|c|c|}
\hline \multicolumn{2}{|l|}{ Article Info } \\
\hline Received: & 19 March 2020 \\
\hline Accepted: & 2 December 2020 \\
\hline Available Online: & 3 January 2021 \\
\hline \multicolumn{2}{|c|}{ DOI: 10.3329/bjp.v16i1.46001 } \\
\hline \multicolumn{2}{|c|}{$\begin{array}{l}\text { Cite this article: } \\
\text { Jin P, Zhao T, Wei Y. Efficacy of beta- } \\
\text { blockers in the treatment of sepsis. } \\
\text { Bangladesh J Pharmacol. 2021; 16: } 1 \\
\text { 18. }\end{array}$} \\
\hline
\end{tabular}

\section{Abstract}

This meta-analysis is to systematically evaluate the efficacy and safety of betablockers in the treatment of sepsis. A total of 17 articles that met the inclusion criteria were included, and 10,385 cases were obtained. The meta-analysis results showed that patients with sepsis with beta-blocker usage had a significantly lower 28-day mortality. The heart rate decreased over time in patients with sepsis using beta-blocker. Moreover, central venous blood oxygen saturation increased after 24, 48,72 hours of treatment; lactic acid and cardiac troponin I decreased after 48,72 hours of treatment; and tumor necrosis factor- $\alpha$, interleukin- $1 \beta$ levels decreased significantly after $12,24,48$, 72 hours of treatment $(\mathrm{p}<0.05)$. In conclusion, beta-blockers reduce 28 -day mortality and heart rate.

\section{Introduction}

Sepsis is a systemic inflammatory response syndrome caused by infection of the body. It is a common complication of severe trauma, hypoxia, reperfusion injury and major surgery. Sepsis accompanied by organ dysfunction can develop into severe sepsis, and hypotension caused by sepsis that has not improved with fluid therapy develops into septic shock. Patient with sepsis has a poor prognosis and a high mortality rate, and is the first cause of death for patients in the intensive care unit (Wang et al., 2012). Published studies have shown that about two-thirds and more of patients with severe sepsis experience varying degrees of heart damage (Muriova et al., 2010), and the pathogenesis may be related to microcirculation disorders (Lorigados et al., 2010), ischemia-reperfusion injury, superoxidative stress (Jaffee et al., 2018), changes in catecholamine levels, etc.

Beta-blocker selectively binds to beta-adrenergic receptors, so as to antagonize the activation of beta receptor by neurotransmitter and catecholamine (Ogrodowczyk et al., 2016). A number of clinical trials assessed in the previous meta-analysis showed beneficial results for beta-blocker usage in the patients with sepsis (Lee et al.,
2019). The purpose of this study is to systematically evaluate the efficacy and safety of beta-blockers in the treatment of sepsis with a view to provide more reliable evidence for its clinical practice and further research.

\section{Materials and Methods}

\section{Retrieval strategy}

Computer search of MedLine, ISI Web of science, EMbase, Google scholar, Spinger Link, China National Knowledge Infrastructure, Wanfang Database, China Science and Technology Journal Database and Chinese Biomedical Literature Database were done. The time since the database was established until September 10, 2017.

The search is mainly based on the combination of subjective terms and random terms. No search restrictions were imposed, and all research related to the subject were collected as much as possible. The English search terms were "sepsis", "septic shock", "severe sepsis", "beta-blocker", "ß-blocker", "esmolol", "propranolol", "bisoprolol", "atenolol", "metoprolol". The Chinese search terms were “脓毒症”, “严重脓毒症”，“脓毒 
性休克”，“ $\beta$ 受体阻滞剂”，“ $\beta$ 受体阻断剂”，“艾 司洛尔”，“普荎洛尔”，“比索洛尔”，“阿替洛 尔”, “美托洛尔”.

At the same time, we manually searched the references of included research and related reviews to prevent omissions, and contacted experts and corresponding authors in the field to obtain relevant information not found in the above search.

\section{Inclusion criteria}

According to the "International Guidelines for Management of Severe Sepsis and Septic Shock: 2012" (Phillips et al., 2012) and the "Chinese Guidelines for Management of Severe Sepsis and Septic Shock: 2014" (Zhi et al., 2015) published by the Society of Critical Care Medicine, Chinese Medical Association, the followings were included: a) study subjects were patients diagnosed with sepsis or severe sepsis or septic shock; b) intervention was the use of $\beta$-blockers; c) study subjects were adult patients (18 years of age or older); d) types of studies were randomized controlled studies (RCT) and non-randomized prospective and retrospective studies; and e) published collectable full text or original articles.

\section{Exclusion criteria}

Exclusion criteria were as follows: a) patients not diagnosed with sepsis or severe sepsis or septic shock; b) intervention measures without the use of betablockers; c) children (ages less than 18 years old); d) animal experiments; e) individual case reports; f) unable to extract available data from published articles; and g) repeatedly published articles, reviews, and articles with the same clinical data.

\section{Data extraction and quality evaluation}

Two researchers independently searched and read the literature, and evaluated the quality of the obtained literature. The literature obtained as final were crosscheck. If there was any disagreement, find the original evidence and ask the third-party researchers to discuss again to reach an agreement. Relevant data were extracted from the included literature through multiple advanced search engines. If the information was incomplete or in doubt, contacted the author by email or phone to obtain accurate and complete information.

Regarding quality evaluation: For RCT, using the Jadad score system to evaluate the methodological quality of the included literature. 1-3 points were classified as low quality, and 4-7 points were classified as high quality (Jadad et al., 1997); for non-randomized prospective and retrospective studies, the Newcastle-Ottawa Scale (NOS) scale recommended by the Cochrane Collaboration for the quality evaluation of non-random research methodologies was used to evaluate the quality of the included studies. 0-5 points were classified as low quality, 6-9 points were classified as high quality (Stang, 2010).

\section{Statistical analysis}

Statistical analysis was performed using STATA 11.0 software. The measurement data were expressed as standardized mean difference (SMD) and its 95\% CI as the effect size, and the count data uses odd ratios (OR) and its $95 \% \mathrm{CI}$ as the effect size. The heterogeneity between the results of the included studies was statistically analyzed using the $\chi^{2}$ test, with a significance level of $a=0.1$. When there was statistical homogeneity between the studies (when $p>0.1, I^{2}<50 \%$ ), a fixed effect model was used for analysis. If there was statistical heterogeneity between the studies (when $\mathrm{p} \leq 0.1, I^{2}>50 \%$ ), a random effect model was used for analysis. A p-value $<0.05$ was considered to be statistically significant.

\section{Results}

\section{Literature search results}

At first, 852 related studies were retrieved. The duplicate publications were removed. Abstracts and case reports were excluded from the irrelevant studies. A total of 379 studies were initially included. After further reading, after layer-by-layer screening, 17 studies were finally included. The literature screening process and results were shown in Figure 1.

\section{Basic characteristics and quality evaluation of included studies}

The 17 included articles included RCT and nonrandomized prospective and retrospective studies. Of these, there were 7 RCTs (Gong et al., 2013; Morelli et al., 2013; Ma, 2014; Yang et al., 2014; Gao et al., 2015; Liang et al., 2015; Xinqiang et al., 2015), 6 prospective studies (Gore and Wolfe, 2006; Balik et al., 2012; Chen et al., 2013; Tao et al., 2015; Morelli et al., 2016; Shang et al., 2016), and 4 retrospective studies (Schmittinger et al., 2008; Gutierrez et al., 2009; Macchia et al., 2012; Wei et al., 2013). There were no statistically significant differences in age, gender, and vital signs between the experimental group and the control group in the included studies. The baselines between the groups were consistent and had good comparability. The basic characteristics of the included studies were shown in Table I.

The results of the methodological study on quality evaluation of the included studies were shown in Table II and Table III. The 7 RCT studies used the Jadad scoring system for quality evaluation, of which 5 studies were $\geq 4$ points and 2 studies were 3 points, indicated that the quality of the included articles were 


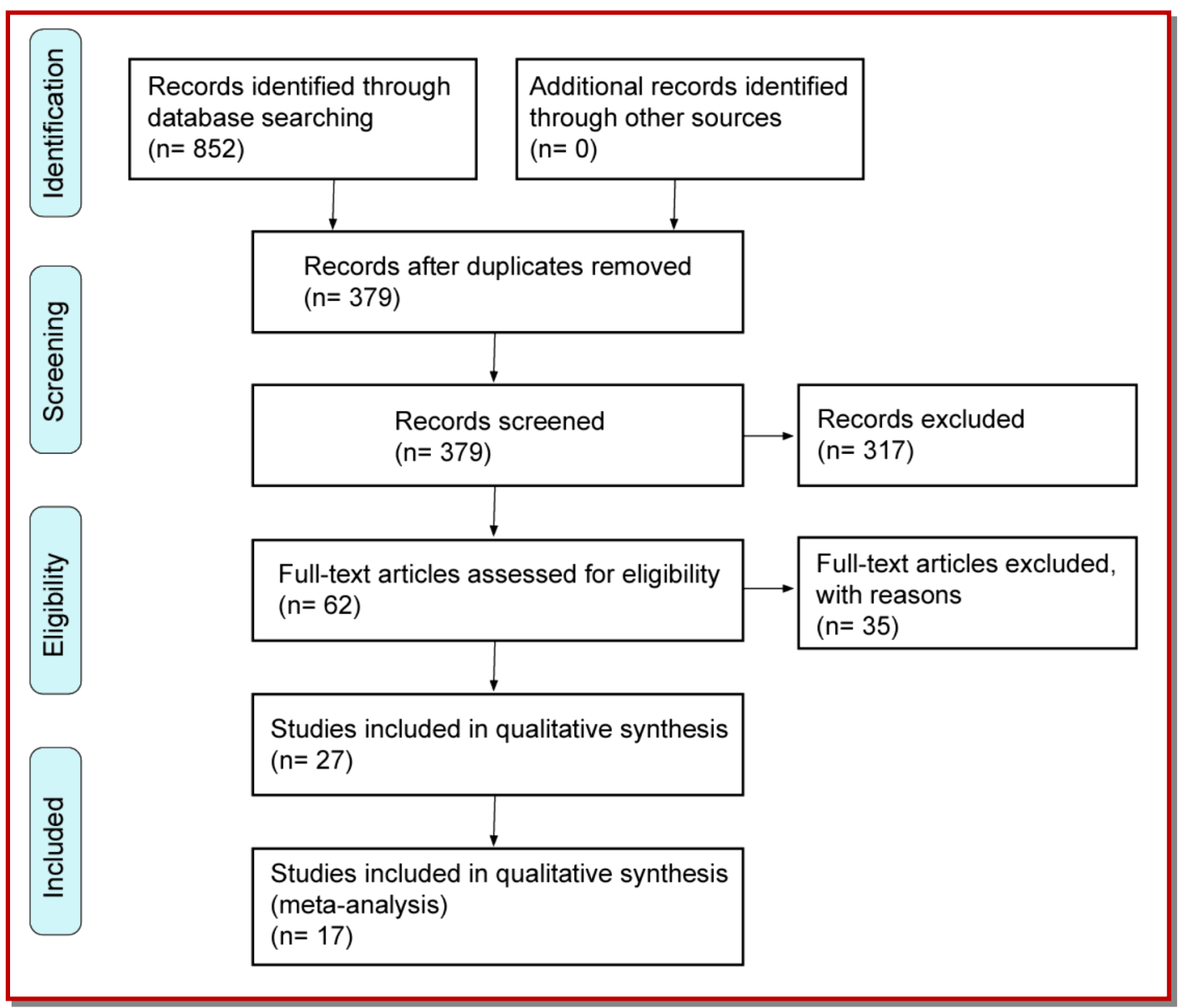

Figure 1: Flow diagram of included studies

good. The confidence level of the results was high.

\section{Meta-analysis results}

\section{Main outcome indicators (28-day mortality)}

Comparison of 28-day mortality in 7 included studies showed that there was heterogeneity among groups $\left(I^{2}=80.4 \%\right)$ and were analyzed using a random effects model. Meta-analysis results showed that there was a statistically significant difference in mortality between the experimental group and the control group [OR (95\% $C I)=0.525(0.263,0.787), \mathrm{p}<0.001]$, indicated that betablockers can reduce the sepsis mortality (Figure 2).

\section{Secondary outcome indicators}

\section{Hemodynamic indicators (heart rate)}

Twelve articles reported the heart rate of the two groups, of which the 2, 3, and 4 hours groups were homogeneous between studies and combined using a fixed effect model; The 6, 12, 24, 48, and 72 hours groups were heterogeneous, and they were combined using a random effects model. Meta-analysis results showed that the SMD $(95 \% \mathrm{CI})$ of heart rate after each time point were $[-1.633(-2.283,-0.984)],[-1.653(-2.346$, $0.960)],[-2.537(-3.044,-2.030)],[-1.346(-2.335,-0.356)],[-$
$1.484(-2.027,-0.940)],[-2.051(-2.570,-1.531)]$, [-1.946 ($2.652,-1.239)],[-2.701(-3.552,-1.851)]($ all $\mathrm{p}<0.05)$, the difference was statistically significant, suggested that the use of beta-blockers is meaningful for slowing the heart rate of patients with sepsis (Figure 3).

\section{Mean arterial pressure}

Seven articles reported the mean arterial pressure of the two groups. The study groups at each time point were homogeneous, and they were combined using a fixed effect model. Meta-analysis results showed that after 24 hours of treatment, the mean arterial pressure in the experimental group was lower than that in the control group, and the difference was statistically significant $(\mathrm{SMD}=-0.217,95 \% \mathrm{CI}=-0.361 \sim-0.072, \mathrm{p}=0.003)$. There was no significant difference in mean arterial pressure results between the two groups of treatments at other time points (Figure 4).

\section{Central venous pressure}

Eight articles reported central venous pressure in the two groups, of which the 4 and 12 hours groups were homogeneous and combined using a fixed effect model; the 24,48 , and 72 hours groups were heterogeneous, and were combined using random effects model. Meta- 


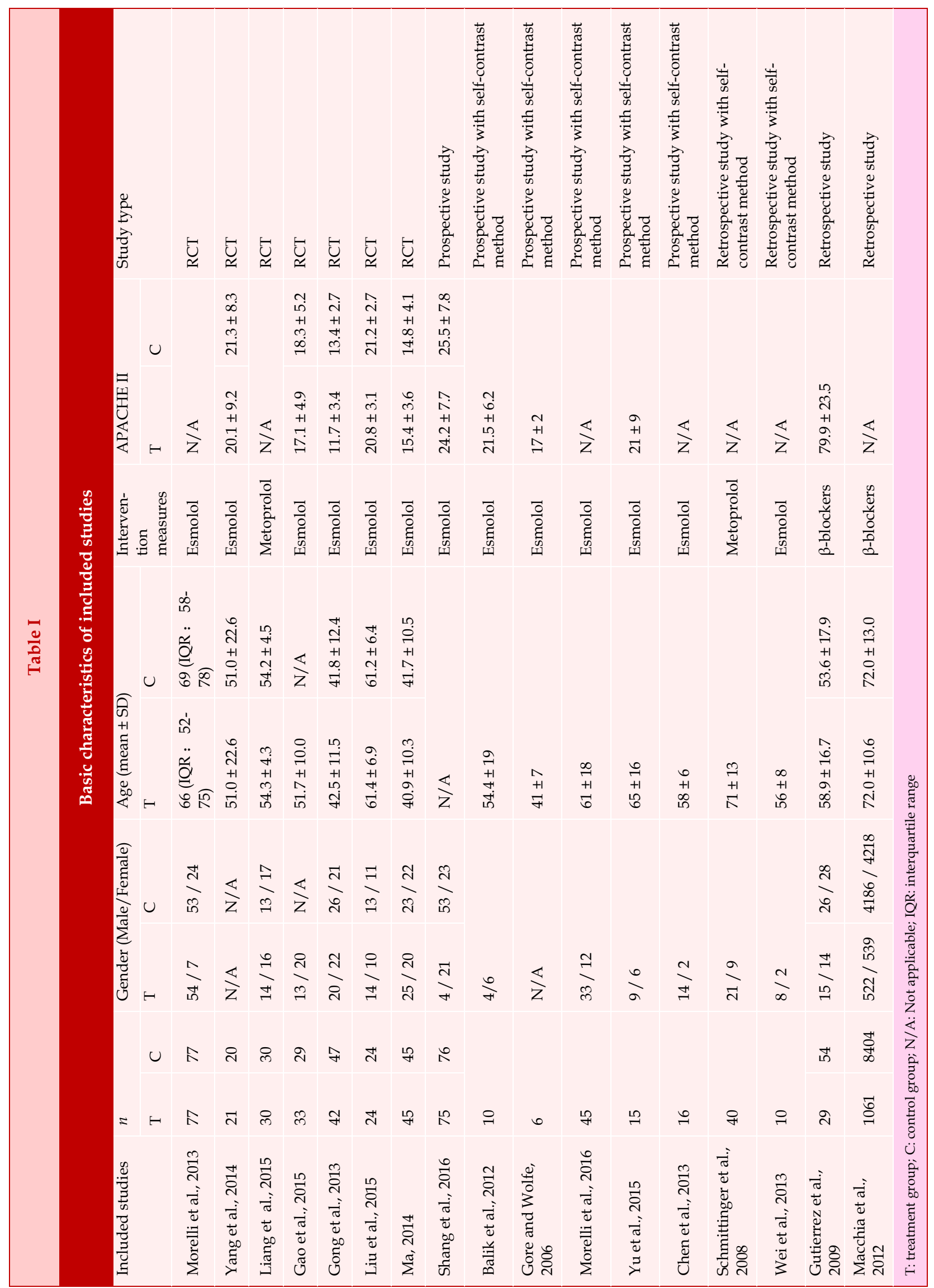


Table II

Using the Jadad scoring system to evaluate the quality of included RCT studies

\begin{tabular}{|c|c|c|c|c|c|c|}
\hline Studies & Random method & $\begin{array}{l}\text { Allocation conceal- } \\
\text { ment }\end{array}$ & Blinding & Withdrew/lost & Scores & $\begin{array}{l}\text { Quality } \\
\text { grade }\end{array}$ \\
\hline Morelli et al., 2013 & Appropriate & Appropriate & Appropriate & Described & 7 & High \\
\hline Yang et al., 2014 & Appropriate & Unclear & Unclear & Not described & 4 & High \\
\hline Liang et al., 2015 & Appropriate & Unclear & Unclear & Not described & 4 & High \\
\hline Gao et al., 2015 & Appropriate & Unclear & Unclear & Described & 5 & High \\
\hline Gong et al., 2013 & Unclear & Unclear & Unclear & Not described & 3 & Low \\
\hline Liu et al., 2015 & Appropriate & Appropriate & Appropriate & Not described & 6 & High \\
\hline Ma, 2014 & Unclear & Unclear & Unclear & Not described & 3 & Low \\
\hline
\end{tabular}

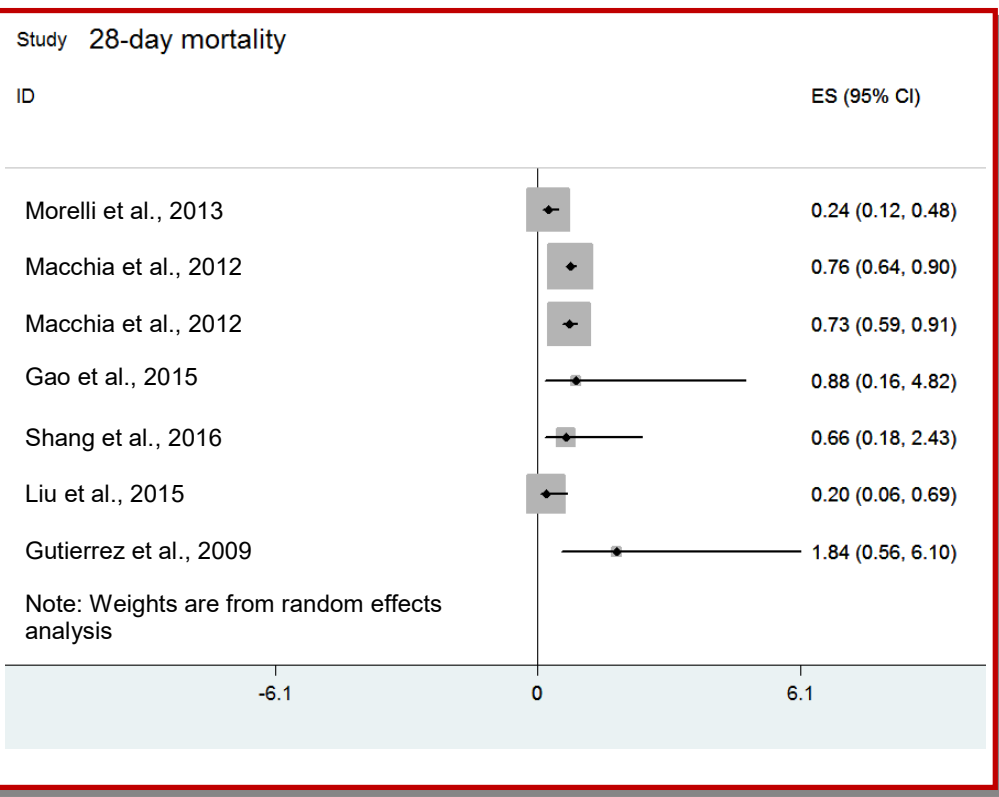

Figure 2: Meta-analysis of beta-blocker on the 28-day mortality

analysis results showed that there was no significant difference in central venous pressure results between the experimental group and the control group at each time point $(\mathrm{p}>0.05)$ (Figure 5).

\section{Cardiac index}

Six articles reported the cardiac index of the two groups, of which the 3 and 6 hours groups were homogeneous between studies and were combined using a fixed effect model; the 12, 24, 48, and 72 hours groups were heterogeneous, and they were combined using a random effects model. Meta-analysis results showed that there was no significant difference in cardiac index between the experimental group and the control group at each time point $(\mathrm{p}>0.05)$ (Figure 6).

\section{Stroke volume index}

Five articles reported the stroke volume index of the two groups, of which the 3 hours group was homogeneous between studies and combined using a fixed effect model; the 12, 24, 48, and 72 hours groups were heterogeneous, and they were combined using a random effects model. Meta-analysis results showed that there was no significant difference in the stroke volume index between the experimental group and the control group at each time point $(\mathrm{p}>0.05)$ (Figure 7).

\section{Systemic vascular resistance index}

Six articles reported the systemic vascular resistance index of the two groups. The studies were homogeneous at each time point and were combined using a fixed effect model. Meta-analysis showed that there was no significant difference in systemic vascular resistance index between the experimental group and the control group at each time point $(\mathrm{p}>0.05)$ (Figure 8).

\section{Noradrenaline dosage}

Two articles reported norepinephrine dosage in the two 


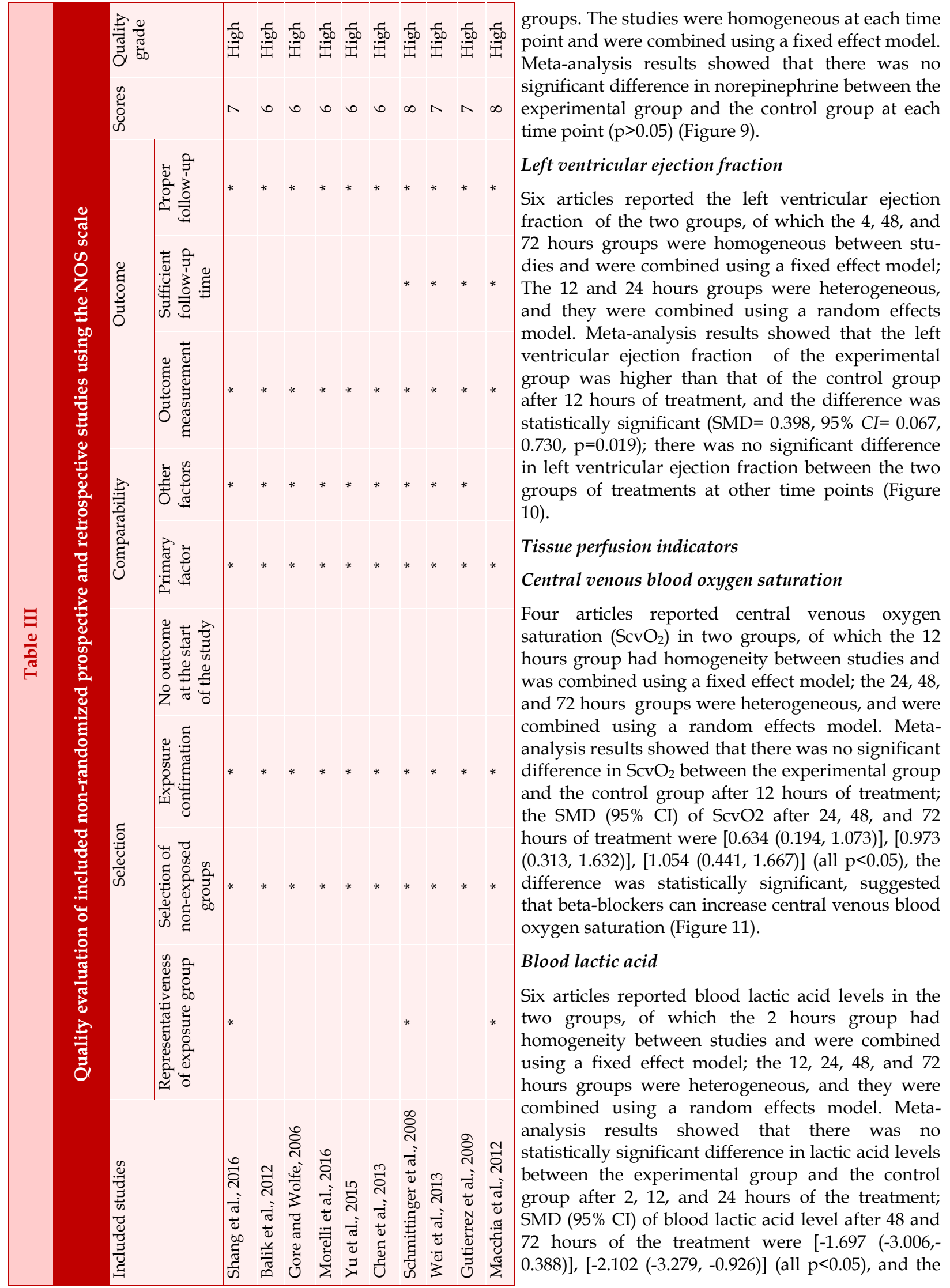




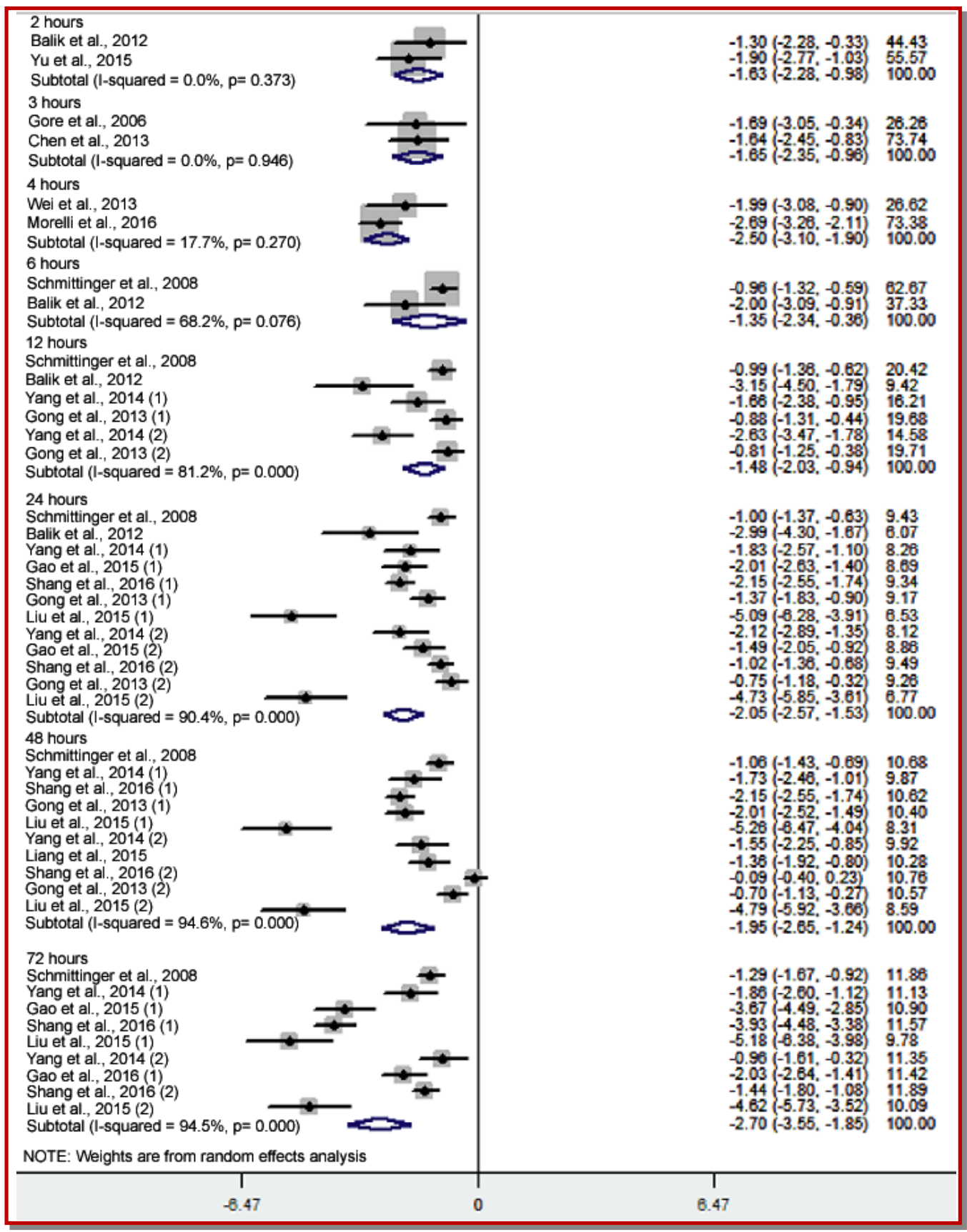

Figure 3: Meta-analysis of beta-blocker on the heart rate (digit within the parenthesis means the number of studies for comparison)

difference was statistically significant (Figure 12).

\section{Other physiological indicators}

\section{Cardiac troponin I}

Two articles reported cardiac troponin I (cTnI) in two groups, of which the 12 hours group had homogeneity between studies and was combined using a fixed effect model; the 24, 48, and 72 hours groups were heterogeneous, and were combined using a random effects model. Meta-analysis results showed that the
SMD $(95 \% C I)$ of cTnI after 48 and 72 hours of the treatment were $[-1.217(-2.282,-0.151)],[-1.725(-2.579$, $0.872)]($ all $p<0.05)$ and the difference was statistically significant; there was no significant difference in cTnI between the two groups of treatments at other time points (Figure 13).

\section{Tumor necrosis factor-a}

Three articles reported tumor necrosis factor-a (TNF-a) in two groups, of which the 12 and 24 hours groups had 


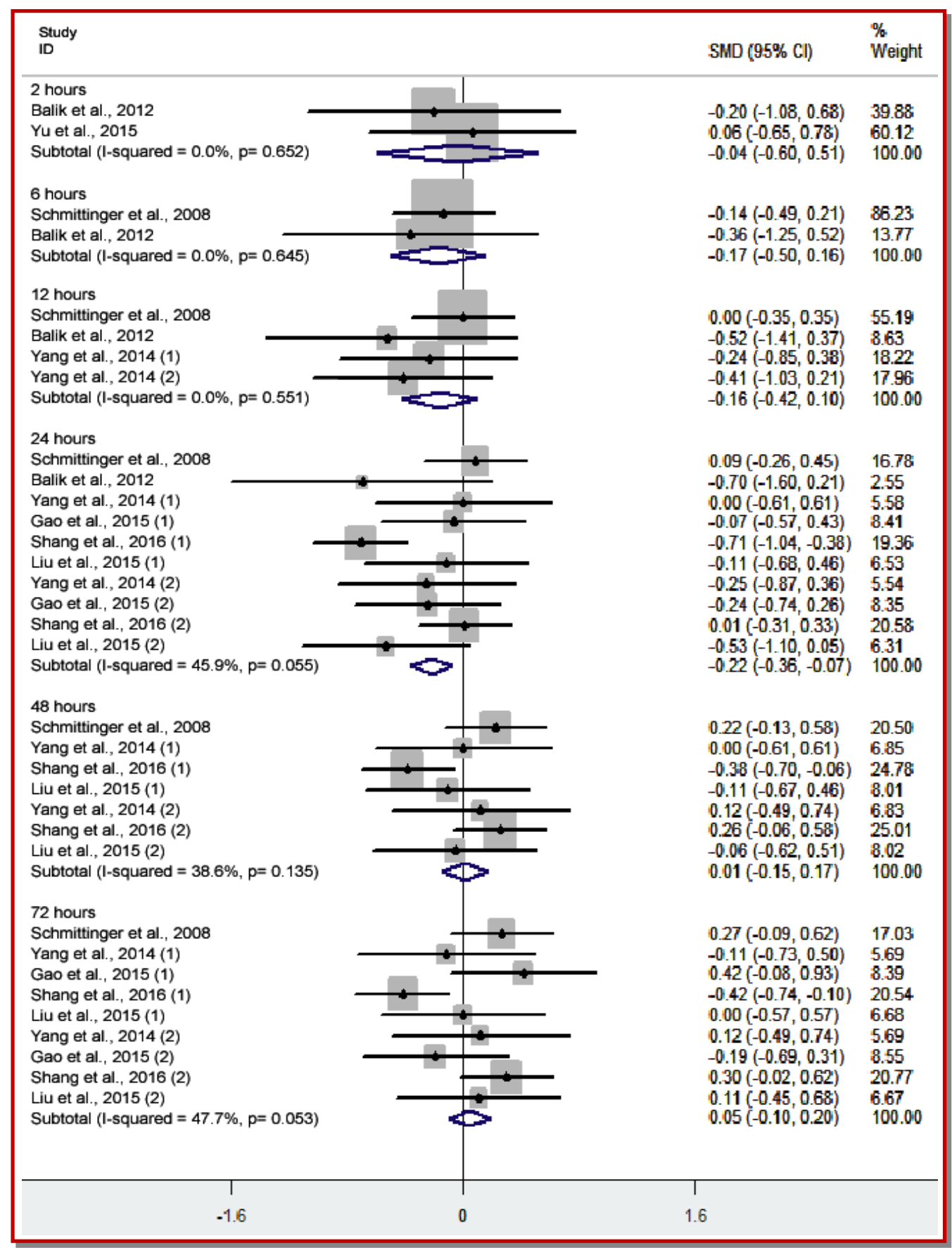

Figure 4: Meta-analysis of $\beta$-blocker on the mean arterial pressure (digit within the parenthesis means the number of studies for comparison)

homogeneity between studies and were combined using a fixed effect model; The 48 and 72 hours groups were heterogeneous, and they were combined using a random effects model. Meta-analysis results showed that compared with the control group, the levels of TNF -a decreased significantly at 12, 24, 48, and 72 hours of the treatment in the experimental group, and the difference between the experimental group and the control group was statistically significant $(\mathrm{p}<0.05)$ (Figure 14).

\section{Interleukin-1 $\beta$}

Three articles reported interleukin-1 $\beta$ (IL-1 $\beta$ ) in the two groups. The study groups at each time point were heterogeneous and were combined using a random effects model. Meta-analysis results showed that compared with the control group, the IL-1 $\beta$ level in the experimental group decreased significantly at 12, 24, 48, 72 hours of the treatment, and the difference between the experimental group and the control group was 


\begin{tabular}{|c|c|c|}
\hline $\begin{array}{l}\text { Study } \\
\text { ID }\end{array}$ & $\mathrm{SMD}(95 \% \mathrm{Cl})$ & $\begin{array}{l}\% \\
\text { Weight }\end{array}$ \\
\hline \multicolumn{3}{|l|}{4 hours } \\
\hline Wei et al., 2013 & $-0.12(-1.00,0.75)$ & 18.15 \\
\hline Morelli et al., 2016 & $0.00(-0.41,0.41)$ & 81.85 \\
\hline Subtotal $(1-$ squared $=0.0 \%, p=0.804)$ & $-0.02(-0.40,0.35)$ & 100.00 \\
\hline \multicolumn{3}{|l|}{12 hours } \\
\hline Schmittinger et al., 2008 & $0.00(-0.35,0.35)$ & 60.15 \\
\hline Yang et al., 2014 (1) & $0.07(-0.54,0.69)$ & 19.99 \\
\hline Yang et al., 2014 (2) & $0.23(-0.38,0.85)$ & 19.86 \\
\hline Subtotal $(1-$ squared $=0.0 \%, p=0.815)$ & $0.06(-0.21,0.33)$ & 100.00 \\
\hline \multicolumn{3}{|l|}{24 hours } \\
\hline \multicolumn{3}{|l|}{ Schmittinger et al., 2008} \\
\hline \multicolumn{3}{|l|}{ Yang et al., 2014 (1) } \\
\hline \multicolumn{3}{|c|}{$0.19(-0.31,0.69) \quad 10.87$} \\
\hline \multicolumn{3}{|c|}{$-0.95(-1.28,-0.61) \quad 13.21$} \\
\hline \multicolumn{3}{|c|}{$0.23(-0.34,0.80) \quad 9.94$} \\
\hline \multicolumn{3}{|l|}{ Yang et al., 2014 (2) } \\
\hline \multicolumn{3}{|l|}{ Gao et al., 2015 (2) } \\
\hline \multicolumn{3}{|l|}{ Shang et al., 2016 (2) } \\
\hline \multicolumn{3}{|l|}{ Liu et al., $2015(2)$} \\
\hline \multicolumn{3}{|l|}{ Subtotal $(\mathrm{l}-$ squared $=72.1 \%, p=0.000)$} \\
\hline \multicolumn{3}{|l|}{48 hours } \\
\hline \multicolumn{3}{|l|}{ Schmittinger et al., 2008} \\
\hline \multicolumn{3}{|c|}{$-0.07(-0.68,0.54) \quad 12.33$} \\
\hline \multicolumn{3}{|c|}{$-0.96(-1.30,-0.63) \quad 16.49$} \\
\hline \multicolumn{3}{|c|}{$0.07(-0.50,0.63) \quad 13.02$} \\
\hline \multicolumn{3}{|l|}{ Yang et al., 2014 (2) } \\
\hline \multicolumn{3}{|l|}{ Shang et al., 2016 (2) } \\
\hline \multicolumn{3}{|l|}{ Liu et al., 2015 (2) } \\
\hline \multicolumn{3}{|l|}{ Subtotal $(\mathrm{l}-\mathrm{squared}=77.2 \%, \mathrm{p}=0.000)$} \\
\hline \multicolumn{3}{|l|}{72 hours } \\
\hline \multicolumn{3}{|c|}{$-0.67(-1.03,-0.3 .1) \quad 12.24$} \\
\hline \multicolumn{3}{|c|}{$0.50(-0.12,1.12) \quad 9.93$} \\
\hline \multicolumn{3}{|c|}{$0.33(-0.17,0.83) \quad 11.02$} \\
\hline Shang et al., 2016 & $-1.07(-1.41,-0.73)$ & 12.38 \\
\hline Liu et al., 2015 (1) & $0.30(-0.27,0.87)$ & 10.41 \\
\hline Yang et al., 2014 (2) & $0.31(-0.31,0.92)$ & 9.99 \\
\hline Gao et al., 2015 (2) & $-0.07(-0.57,0.43)$ & 11.05 \\
\hline Shang et al., 2016 (2) & $-0.09(-0.41,0.23)$ & 12.55 \\
\hline Liu et al., $2015(2)$ & $-0.15(-0.72,0.41)$ & 10.43 \\
\hline Subtotal $(\mathrm{l}-$ squared $=82.7 \%, \mathrm{p}=0.000)$ & $-0.10(-0.47,0.27)$ & 100.00 \\
\hline NOTE: Weights are from random effects ana & & \\
\hline 1 & 1 & \\
\hline-1.41 & 1.41 & \\
\hline
\end{tabular}

Figure 5: Meta-analysis of beta-blocker on the central venous pressure (digit within the parenthesis means the number of studies for comparison)

statistically significant $(\mathrm{p}<0.05)$ (Figure 15).

\section{Discussion}

In recent years, with the continuous deepening of the understanding of sepsis, the research of beta-blockers in the field of intensive medicine has gradually increased. The analysis of the efficacy of beta-blockers in the treatment of sepsis in this study showed that beta- blockers can effectively reduce the 28-day mortality rate, heart rate, blood lactic acid, cTnI, TNF- $\alpha$ and IL-1 $\beta$ levels in patients with sepsis, and can effectively increase left ventricular ejection fraction and $\mathrm{ScvO}_{2}$ levels, and have little effect on central venous pressure, cardiac index, stroke volume index, systemic vascular resistance index and norepinephrine. Its role in reducing mean arterial pressure levels at 24 hours of the treatment remains to be confirmed. 


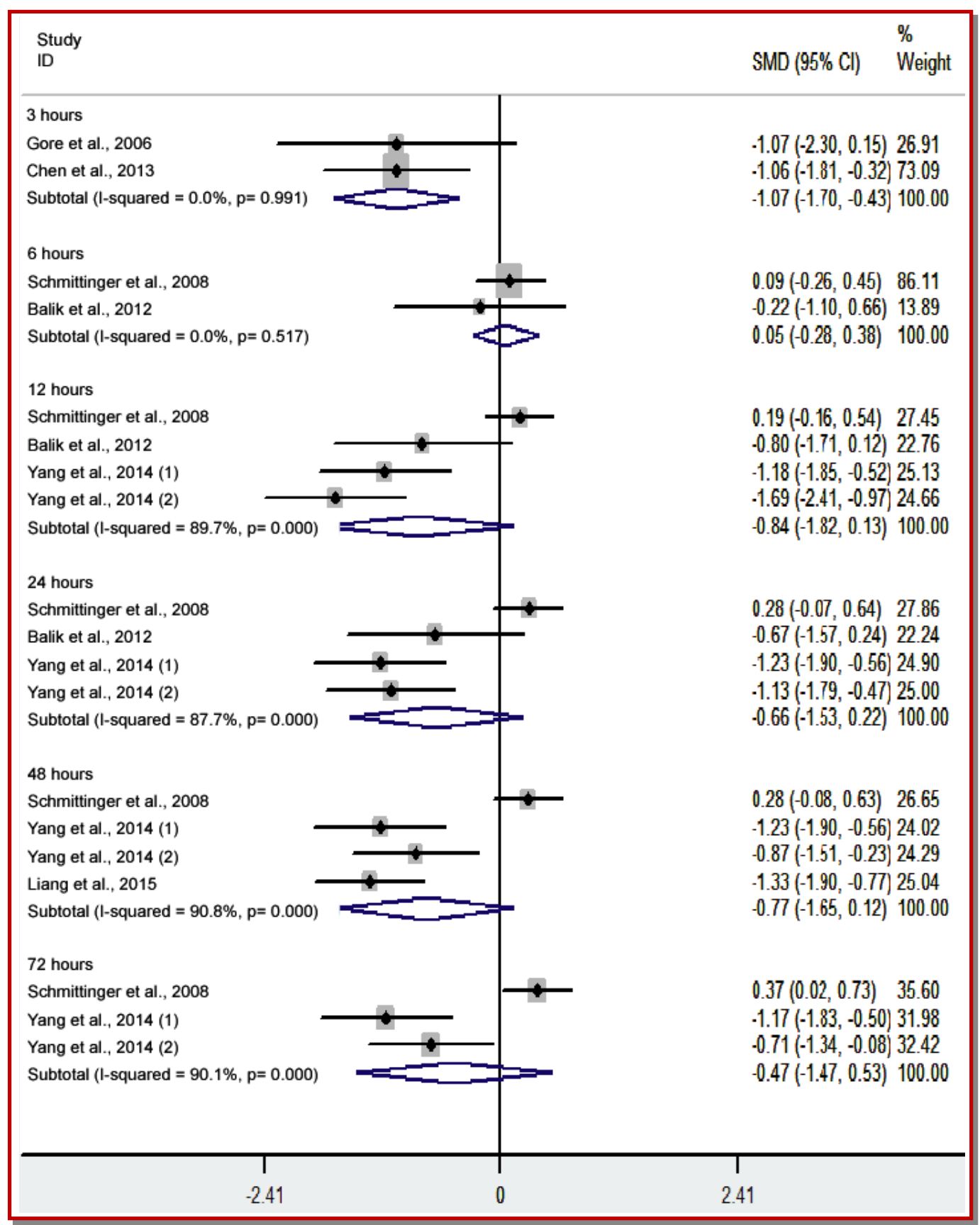

Figure 6: Meta-analysis of beta-blocker on the cardiac index (digit within the parenthesis means the number of studies for comparison)

Previous study has suggested that patients with severe sepsis who have taken beta-blockers for a long time before admission have a better clinical prognosis than those who have not taken beta-blockers (Macchia et al., 2012). Seven studies included in this study reported 28day mortality, and analysis showed that beta-blockers can effectively reduce 28 -day mortality in patients with sepsis. This study confirmed that beta-blockers can significantly improve the clinical prognosis of patients with sepsis.
Studies have shown that beta-blockers can improve immune function, cardiovascular function and coagulation function in patients with sepsis ( $\mathrm{Xu}$ et al., 2015; Duff et al., 2016; Schlager et al., 2016). However, due to its direct effect on the heart, sometimes it can cause or exacerbate hypotension, which makes clinical physicians are very cautious about the application of this kind of drugs. The slowing of heart rate has positive effect in preventing myocardial damage and malignant arrhythmia caused by sepsis, and this study confirmed that beta-blockers did not show significant 


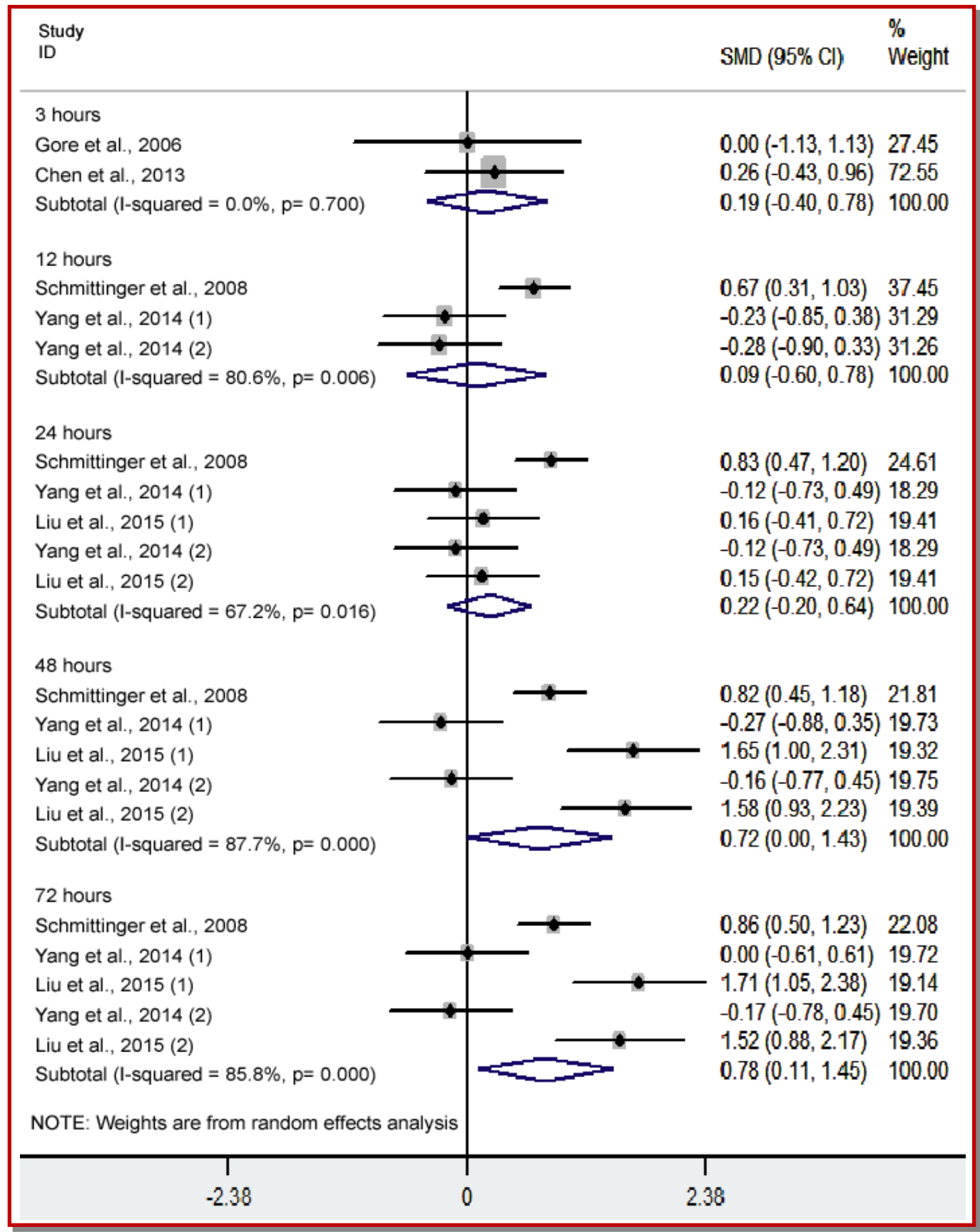

Figure 7: Meta-analysis of $\beta$-blocker on the stroke volume index (digit within the parenthesis means the number of studies for comparison)

changes in central venous pressure, cardiac index, stroke volume index, systemic vascular resistance index and norepinephrine while heart rate decreased, which suggested that beta-blockers can maintain hemodynamic stability while reducing heart rate, which may be closely related to improving the clinical prognosis of patients.

In the early stages of severe infection and septic shock, the sympathetic nervous system is over-activated, catecholamines are released excessively, tissues, organs and microcirculation are in an hypermetabolism state, and oxygen demand exceeds oxygen supply. Even if blood pressure and heart rate are in the normal range, $\mathrm{ScvO}_{2}$ may decrease. Blood lactic acid level and $\mathrm{ScvO}_{2}$ can reflect the patient's tissue perfusion and oxygen metabolism at an early stage (Trzeciak et al., 2007). When the body's oxygen supply decreases or the oxygen demand exceeds the oxygen supply, $\mathrm{ScvO}_{2}$ decreases and blood lactic acid levels increase. Lactic acid is a product of anaerobic metabolism, and its 


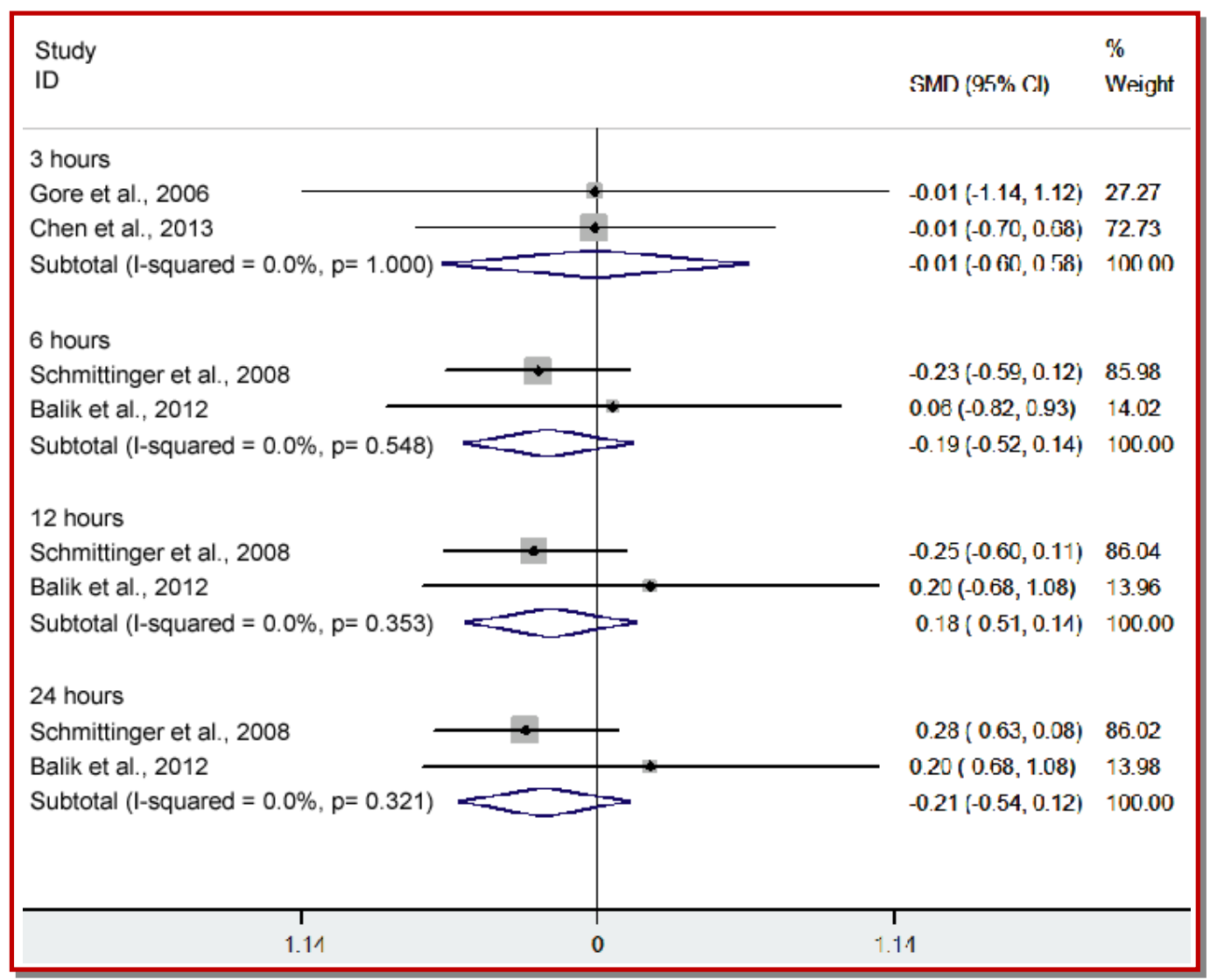

Figure 8: Meta-analysis of $\beta$-blocker on the systemic vascular resistance index (digit within the parenthesis means the number of studies for comparison)

concentration is a common indicator of tissue oxygen supply. The change of its value is related to the disease outcome and prognosis (Jansen et al., 2009). Only by improving the hypoperfusion of peripheral tissues and correcting the abnormal cellular oxygen metabolism can the clinical outcome and prognosis be improved (Carre and Singer, 2008). The results of this study found that $\mathrm{ScvO}_{2}$ in the experimental group was significantly higher than that in the control group after 24 hours of the treatment, and the level of lactic acid in the experimental group was significantly lower than that in the control group after 48 hours of the treatment. It is shown that beta-blockers can improve tissue oxygen metabolism, correct cellular oxygen metabolism abnormalities, and ultimately improve the outcome and prognosis of patients with sepsis on the basis of controlling heart rate, maintaining hemodynamics and improving cardiac function.

An increase in cTnI is indicative of a poor prognosis in patients with sepsis (Lazzeri et al., 2008). The results of this study found that cTnI in the experimental group was significantly lower than that in the control group after 48 hours of treatment, further confirmed that $\beta$ blockers can effectively reduce the degree of myocardial injury in patients with sepsis and have a protective effect on the myocardium. In the initial stage of sepsis, it is mainly characterized by the release of a large number of pro-inflammatory mediators (Duncan et al., 2010). The excessive release of inflammatory mediators of TNF- $\alpha$ and IL-1 $\beta$ turn cytokines from protective effect to damaging effect, causes imbalance of proinflammatory/anti-inflammatory mediators and turn into multiple organ failure (Chandra et al., 2006). The results of this study confirmed that, after 12 hours of treatment, the application of beta-blockers can significantly reduce the expression of TNF- $\alpha$ and IL-1 $\beta$, thereby preventing them from progressing to multiple organ failure.

\section{Conclusion}

The usage of beta-blockers can effectively reduce 28day mortality and heart rate, and it has significant effect on central venous blood oxygen saturation, lactic acid, cardiac troponin I, tumor necrosis factor- $\alpha$ and interleukin-1 $\beta$. However, caution should be used in patients with sepsis, especially for severe sepsis and severe shock patient. The timing of application, choice of dosage form, dose selection, and impact on patient prognosis need to be confirmed by further large-scale clinical studies. 


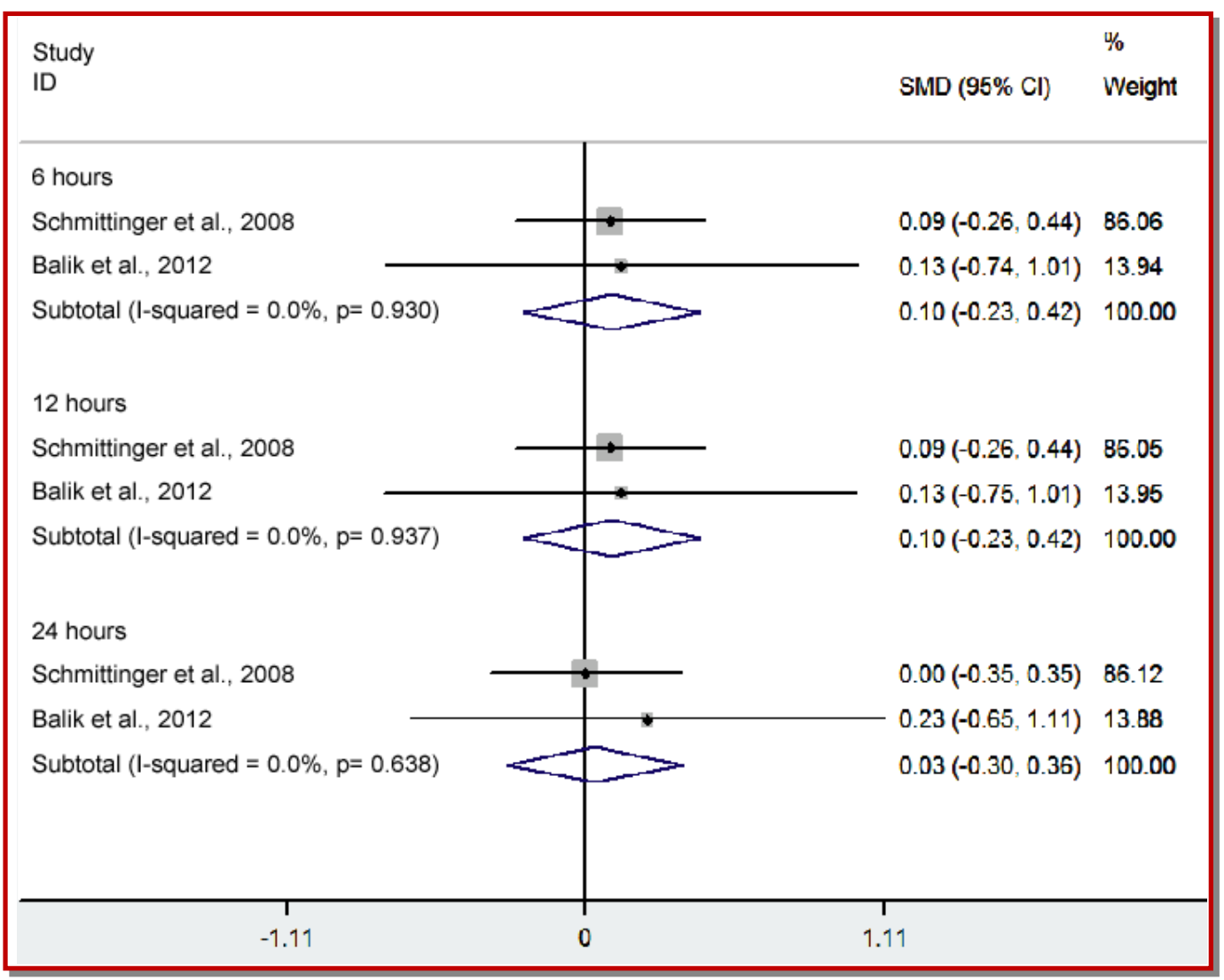

Figure 9: Meta-analysis of beta-blocker on the noradrenaline dosage (digit within the parenthesis means the number of studies for comparison)

\section{Financial Support}

Self-funded

\section{Conflict of Interest}

Authors declare no conflict of interest

\section{References}

Balik M, Rulisek J, Leden P, Zakharchenko M, Otahal M, Bartakova $\mathrm{H}$, Korinek J. Concomitant use of beta- 1 adrenoreceptor blocker and norepinephrine in patients with septic shock. Wien Klin Wochenschr. 2012; 124: 552-56.

Carre JE, Singer M. Cellular energetic metabolism in sepsis: The need for a systems approach. Biochim Biophys Acta. 2008; 1777: 763-71.

Chandra A, Enkhbaatar P, Nakano Y, Traber LD, Traber DL. Sepsis: Emerging role of nitric oxide and selectins. Clinics (Sao Paulo). 2006; 61: 71-76.

Chen JX, Sun J, Liu YY, Jia BH. Effects of adrenergic beta-1 antagonists on hemodynamics of severe septic patients. Zhonghua Yi Xue Za Zhi. 2013; 93: 1243-46.

Duff S, Connolly C, Buggy DJ. Adrenergic, inflammatory, and immune function in the setting of oncological surgery: Their effects on cancer progression and the role of the anesthetic technique in their modulation. Int Anesthesiol Clin. 2016; 54: 48-57.

Duncan DJ, Yang Z, Hopkins PM, Steele DS, Harrison SM. TNF-alpha and IL-1beta increase $\mathrm{Ca}^{2+}$ leak from the sarcoplasmic reticulum and susceptibility to arrhythmia in rat ventricular myocytes. Cell Calcium. 2010; 47: 378-86.

Gao X, Cao W, Guan Y, Luo Y, Lian F, He N, Wang X, Li P. Protective effect of esmolol on myocardial injury in septic patients. Chin J Crit Care Med. 2015; 35: 678-81.

Gong X, Zhang Z, Zhai X, Zhang R. Effects of esmolo on inflammatory responses and left ventricular function in patients with sepsis. Chin J Crit Care Med. 2013; 33: 879-81.

Gore DC, Wolfe RR. Hemodynamic and metabolic effects of selective beta1 adrenergic blockade during sepsis. Surgery 2006; 139: 686-94.

Gutierrez J, Hossam A, Lazarezcu R, Kay E, Rundek T. Effect of beta blockers on sepsis outcome. Med Sci Monit. 2009; 15: Cr499-503.

Jadad AR, Cook DJ, Browman GP. A guide to interpreting discordant systematic reviews. Cmaj. 1997; 156: 1411-16.

Jaffee W, Hodgins S, McGee WT. Tissue edema, fluid balance, and patient outcomes in severe sepsis: An organ systems review. J Intensive Care Med. 2018; 33: 502-09.

Jansen TC, van Bommel J, Bakker J. Blood lactate monitoring in 


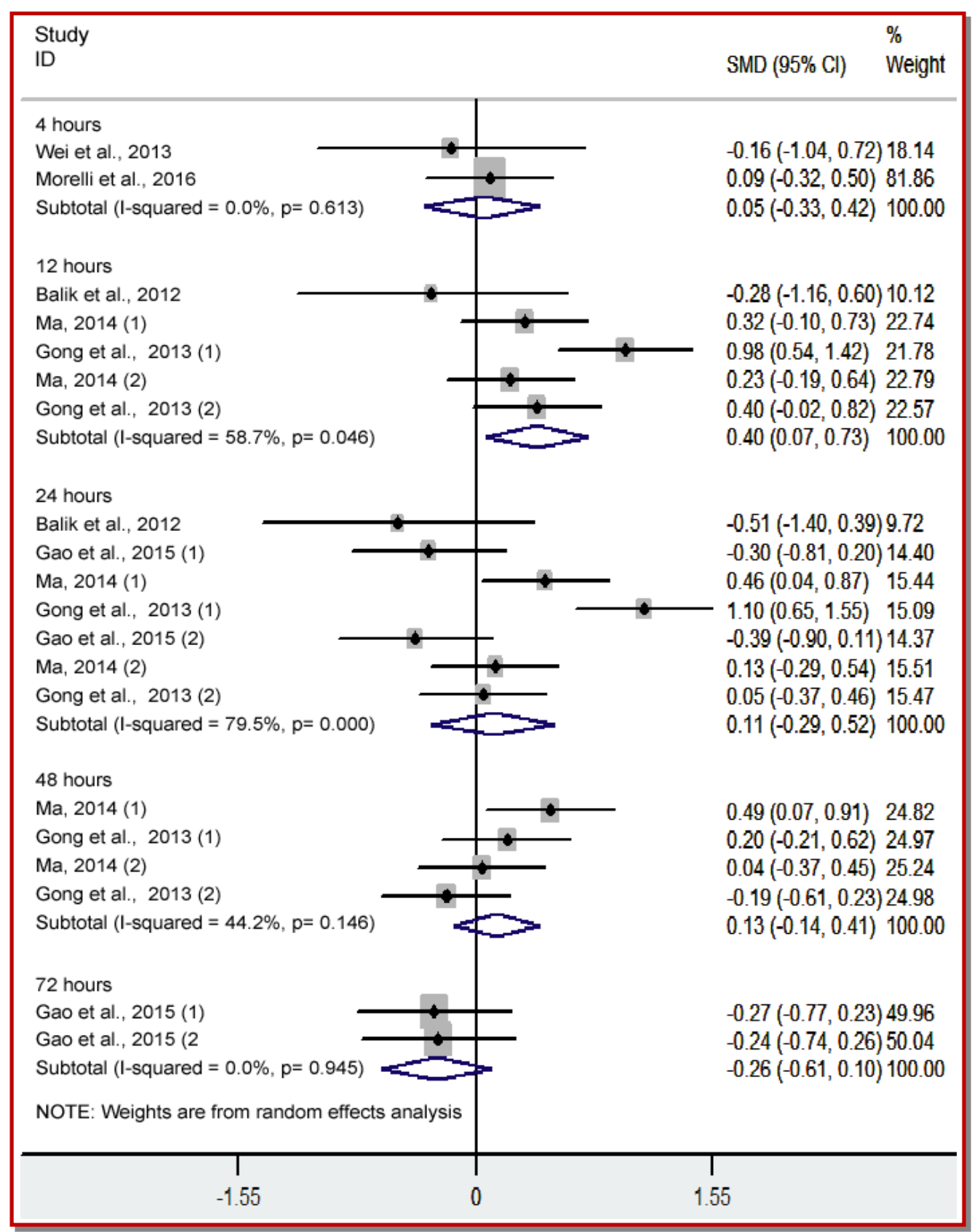

Figure 10: Meta-analysis of beta-blocker on the left ventricular ejection fraction (digit within the parenthesis means the number of studies for comparison)

critically ill patients: A systematic health technology assessment. Crit Care Med. 2009; 37: 2827-39.

Lazzeri C, Bonizzoli M, Cianchi G, Gensini GF, Peris A. Troponin I in the intensive care unit setting: From the heart to the heart. Intern Emerg Med. 2008; 3: 9-16.

Lee YR, Seth MS, Soney D, Dai H. Benefits of beta-blockade in sepsis and septic shock: A systematic review. Clin Drug Investig. 2019; 39: 429-40.

Liang F, Zhang Z, Ye W, Liang W, Cao F. $\beta$-Blockers metoprolol protective effect for heart patients with sepsis. Mod Diagn Treat. 2015; 26: 733-35.
Lorigados CB, Soriano FG, Szabo C. Pathomechanisms of myocardial dysfunction in sepsis. Endocr Metab Immune Disord Drug Targets. 2010; 10: 274-84.

Ma C. The effects of esmolol with intravenous pumping on inflammatory response and cardiac function in patients with sepsis. J Community Med. 2014; 12: 47-48.

Macchia A, Romero M, Comignani PD, Mariani J, D'Ettorre A, Prini N, Santopinto M, Tognoni G. Previous prescription of beta-blockers is associated with reduced mortality among patients hospitalized in intensive care units for sepsis. Crit Care Med. 2012; 40: 2768-72. 


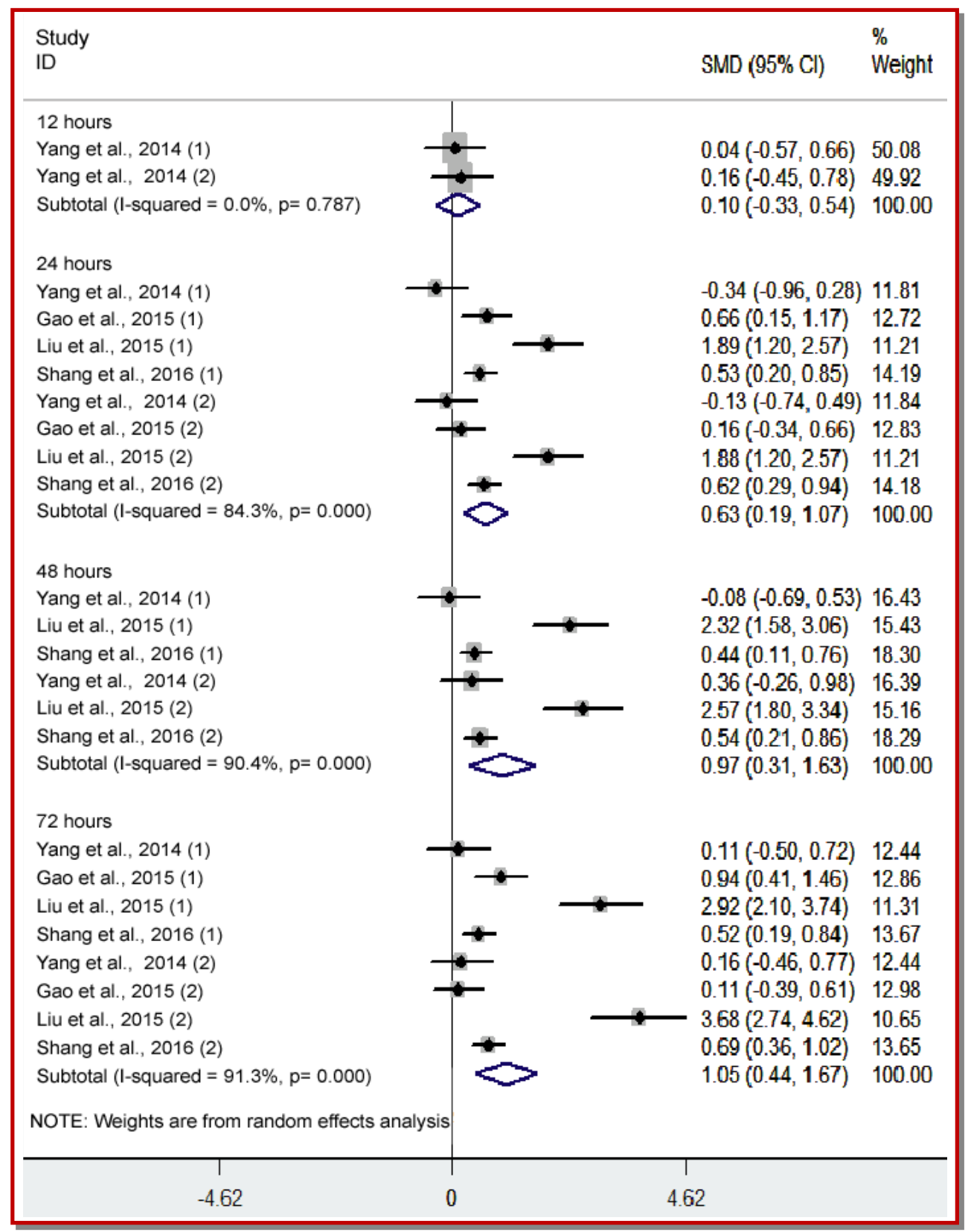

Figure 11: Meta-analysis of beta-blocker on the central venous blood oxygen saturation (digit within the parenthesis means the number of studies for comparison)

Morelli A, Ertmer C, Westphal M, Rehberg S, Kampmeier T, Ligges S, Orecchioni A, D'Egidio A, D'Ippoliti F, Raffone C, Venditti M, Guarracino F, Girardis M, Tritapepe L, Pietropaoli P, Mebazaa A, Singer M. Effect of heart rate control with esmolol on hemodynamic and clinical outcomes in patients with septic shock: A randomized clinical trial. JAMA. 2013; 310: 1683-91.

Morelli A, Singer M, Ranieri VM, D'Egidio A, Mascia L, Orecchioni A, Piscioneri F, Guarracino F, Greco E, Peruzzi M, Biondi-Zoccai G, Frati G, Romano SM. Heart rate reduction with esmolol is associated with improved arterial elastance in patients with septic shock: A prospective observational study. Intensive Care Med. 2016; 42: 1528-34.
Muriova K, Malaska J, Otevrel F, Slezak M, Kratochvil M, Sevik P. Myocardial dysfunction in sepsis: Definition and pathogenetic mechanisms. Vnitr Lek. 2010; 56: 220-25.

Ogrodowczyk M, Dettlaff K, Jelinska A. Beta-blockers: Current state of knowledge and perspectives. Mini Rev Med Chem. 2016; 16: 40-54.

Phillips R, Hancock B, Graham J, Bromham N, Jin H, Berendse S. Prevention and management of neutropenic sepsis in patients with cancer: Summary of NICE guidance. BMJ. 2012; 345: e5368.

Schlager O, Gajdosova Kovacicova L, Senn O, Amann-Vesti B, Wilkinson IB, Jacomella V, Husmann M. Beta-blockers and 


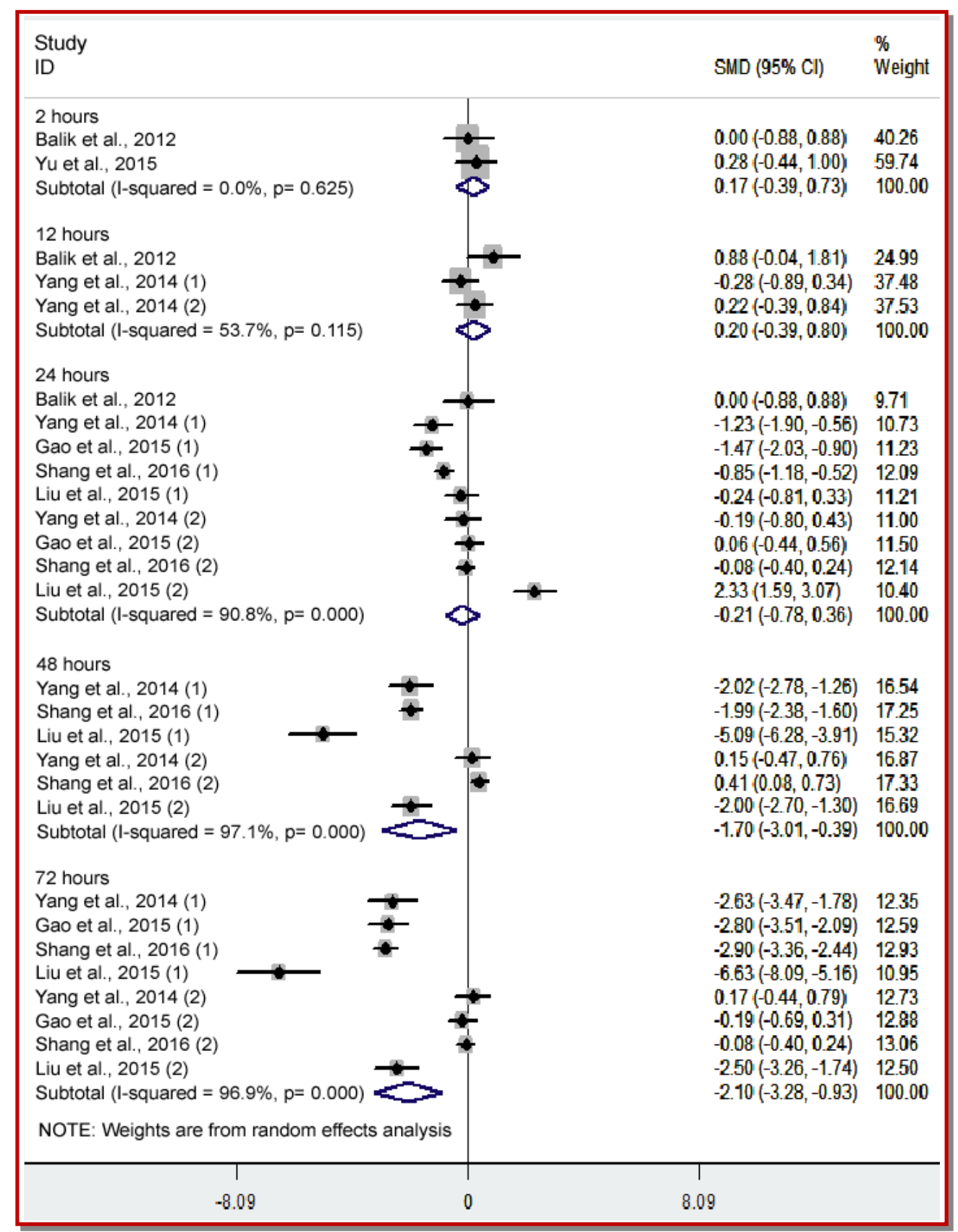

Figure 12: Meta-analysis of beta-blocker on the blood lactic acid (digit within the parenthesis means the number of studies for comparison)

vascular hemodynamics in patients with peripheral arterial disease. J Clin Hypertens (Greenwich). 2016; 18: 1244-49.

Schmittinger CA, Dunser MW, Haller M, Ulmer H, Luckner G, Torgersen C, Jochberger S, Hasibeder WR. Combined milrinone and enteral metoprolol therapy in patients with septic myocardial depression. Crit Care. 2008; 12: R99.

Shang X, Wang K, Xu J, Gong S, Ye Y, Chen K, Lian F, Chen W, $\mathrm{Yu}$ R. The effect of esmolol on tissue perfusion and clinical prognosis of patients with severe sepsis: A prospective cohort study. Biomed Res Int. 2016; 2016: 1038034.

Stang A. Critical evaluation of the Newcastle-Ottawa scale for the assessment of the quality of nonrandomized studies in meta-analyses. Eur J Epidemiol. 2010; 25: 603-05.

Tao Y, Jingyi W, Xiaogan J, Weihua L, Xiaoju J. Effect of esmolol on fluid responsiveness and hemodynamic parameters in patients with septic shock. Zhonghua Wei Zhong Bing Ji Jiu Yi Xue. 2015; 27: 885-89.

Trzeciak S, Dellinger RP, Chansky ME, Arnold RC, Schorr C, Milcarek B, Hollenberg SM, Parrillo JE. Serum lactate as a predictor of mortality in patients with infection. Intensive Care Med. 2007; 33: 970-77.

Wang HE, Shapiro NI, Griffin R, Safford MM, Judd S, Howard 


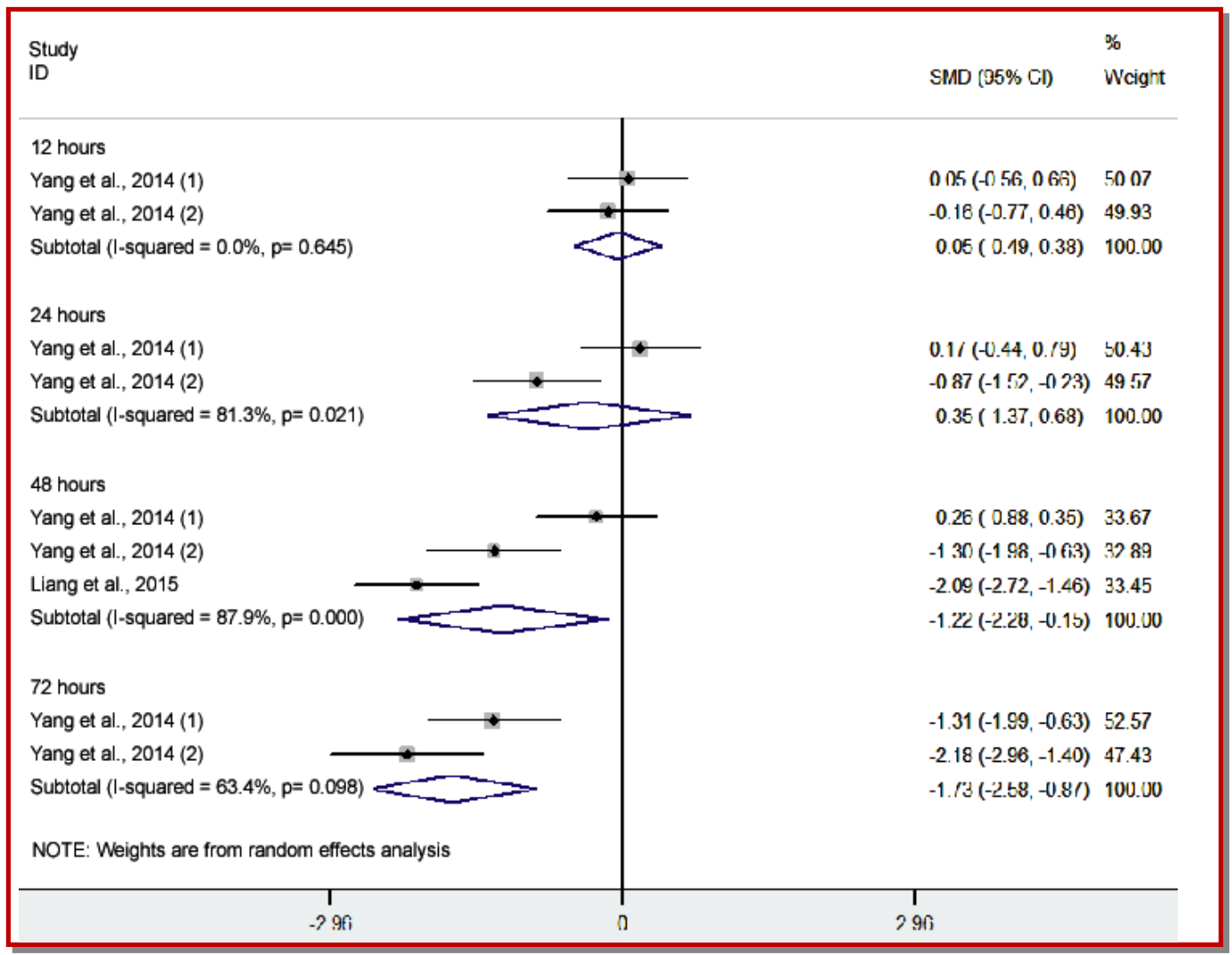

Figure 13: Meta-analysis of $\beta$-blocker on the cardiac troponin I (digit within the parenthesis means the number of studies for comparison)

\begin{tabular}{|c|c|c|}
\hline $\begin{array}{l}\text { Study } \\
\text { ID }\end{array}$ & $\operatorname{SMD}(95 \%$ C $)$ & $\begin{array}{l}\% \\
\text { Weight }\end{array}$ \\
\hline \multicolumn{3}{|l|}{12 hours } \\
\hline Gong et al., 2013 (1) & $-0.69(-1.12,-0.26)$ & 24.94 \\
\hline $\mathrm{Ma}, 2014$ (1) & $-0.57(-0.99,-0.15)$ & 25.78 \\
\hline Gong et al., 2013 (2) & $-0.50(-1.31,-0.17)$ & 23.96 \\
\hline $\mathrm{Ma}, 2014(2)$ & $-069(-111,-026)$ & 25.32 \\
\hline Subtotal (I-squared $=0.0 \%, p=0.749)$ & $0.71(0.92,0.50)$ & 100.00 \\
\hline \multicolumn{3}{|l|}{24 hours } \\
\hline Gao et al., 2015 (1) & $-0.83(-1.35,-0.31)$ & 12.61 \\
\hline Gong et al., 2013 (1) & $-0.57(-0.99,-0.14)$ & 13.93 \\
\hline $\mathrm{Ma}, 2014$ (1) & $0.56(1.40,0.53)$ & $1 / .8 /$ \\
\hline Gao et al., 2015 (2) & $-0.11(-0.91,0.07)$ & 13.39 \\
\hline Gong et al., 2013 (2) & $-0.57(-100,-01.5)$ & 16.91 \\
\hline $\mathrm{Ma}, 2014$ (2) & $0.85(1.29,0.42)$ & 13.29 \\
\hline Subtotal (l-squared $=0.0 \%, p=0.571$ ) & $-0.71(-0.89,-0.52)$ & 100.00 \\
\hline \multicolumn{3}{|l|}{48 hours } \\
\hline Gong et al., 2013 (1) & $-1.79(-2.29,-1.30)$ & 24.61 \\
\hline $\mathrm{Ma}, 2014$ (1) & $-203(-2.54,-1.52)$ & 24.36 \\
\hline Gong et al., 2013 (2) & $-0.71(-1.14,-0.28)$ & 25.55 \\
\hline Ma, 2014 (2) & $-0.50(-1.33,-0.46)$ & 25.48 \\
\hline Subtotal (I-squared $=86.6 \%, p=0.000)$ & $1.35(1.98,0.71)$ & 100.00 \\
\hline \multicolumn{3}{|l|}{72 hours } \\
\hline Gao et al., 2015 (1) & $2.49(3.15,1.82)$ & 49.10 \\
\hline Gao et al., 2015 (2) & $-0.91(-144,-0.39)$ & 50 90 \\
\hline Subtotal (l-squared $=92.4 \%, p=0.000)$ & $-1.69(-3.23,-0.14)$ & 100.00 \\
\hline \multicolumn{3}{|l|}{ NOTE: Weights are from random effects analysis } \\
\hline 11 & 7 & \\
\hline
\end{tabular}

Figure 14: Meta-analysis of $\beta$-blocker on the tumor necrosis factor-a (digit within the parenthesis means the number of studies for comparison) 


\begin{tabular}{|c|c|c|}
\hline $\begin{array}{l}\text { Study } \\
\text { ID }\end{array}$ & $\operatorname{SMD}(95 \% \mathrm{Cl})$ & $\begin{array}{l}\% \\
\text { Weight }\end{array}$ \\
\hline \multicolumn{3}{|l|}{12 hours } \\
\hline Gong et al., 2013 (1) & $0.51(1.04,0.19)$ & 25.80 \\
\hline $\mathrm{Ma}, 2014$ (1) & $-0.78(-1.21,-0.35)$ & 25.61 \\
\hline Gong et al., 2013 (2) & $-1.29(-1.74,-0.83)$ & 21.03 \\
\hline $\mathrm{Ma}, 2014$ (2) & $-1.18(-1.63,-0.73)$ & 24.54 \\
\hline Subtotal $(l-$ squared $=51.0 \%, p=0.106)$ & $-0.96(-1.27,-0.61)$ & 100.00 \\
\hline \multicolumn{3}{|l|}{24 hours } \\
\hline Gao et al., 2015 (1) & $-1.39(-1.94,-0.83)$ & 16.10 \\
\hline Gong et al., 2013 (1) & $-0.28(-0.70,0.13)$ & 17.36 \\
\hline $\mathrm{Ma}, 2014$ (1) & $-1.03(-1.48,-0.59)$ & 17.17 \\
\hline Gao et al., 2015 (2) & $-1.81(-2.41,-1.22)$ & 15.73 \\
\hline Gong et al., 2013 (2) & $-217(-270,-1(74)$ & 16.99 \\
\hline $\mathrm{Ma}, 2014(2)$ & $-0.69(-1.32,-0.46)$ & 17.24 \\
\hline Subtotal $(\mathrm{l}-\mathrm{squared}=86.8 \%, p=0.000)$ & $-1>4(-179,-070)$ & 10000 \\
\hline \multicolumn{3}{|l|}{48 hours } \\
\hline Gong et al., 2013 (1) & $-4.37(-5,14,-360)$ & 24.33 \\
\hline $\mathrm{Ma}, 2014$ (1) & $-27.3(-3.31,-215)$ & 2505 \\
\hline Gong et al., 2013 (2) & $-0.65(-1.08,-0.23)$ & $2 b .49$ \\
\hline $\mathrm{Ma}, 2014(2)$ & $-248(-31) 3,-1 ! 93)$ & 313 \\
\hline Subtotal $(l-$ squared $=96.4 \%, p=0.000)$ & $-2.14(-40 ?,-10.5)$ & 10000 \\
\hline \multicolumn{3}{|l|}{72 hours } \\
\hline Gao et al., 2015 (1) & $8.28(9.84,6.72)$ & 49.08 \\
\hline Gao et al., $2015(2)$ & $-3.13(-3.88,-2.38)$ & 5). 52 \\
\hline \multirow{2}{*}{$\begin{array}{l}\text { Subtotal }(\mathrm{l}-\mathrm{squared}=97.0 \%, \mathrm{p}=0.000) \\
\text { NOTE: Weights are from random effects analysis }\end{array}$} & $5.66(10.70,0.62)$ & 100.00 \\
\hline & & \\
\hline 1 & 1 & \\
\hline-10.7 & 10.7 & \\
\hline
\end{tabular}

Figure 15: Meta-analysis of beta-blocker on the interleukin-1 $\beta$ (digit within the parenthesis means the number of studies for comparison)

G. Chronic medical conditions and risk of sepsis. PLoS One. 2012; 7: e48307.

Wei F, Dong H, Lu L, Xue H. Protective effect of esmolol on myocardium of systemic sepsis patients. World Latest Med Inf. 2013; 13: 18-19.

Xinqiang L, Weiping H, Miaoyun W, Wenxin Z, Wenqiang J, Shenglong C, Juhao Z, Hongki Z. Esmolol improves clinical outcome and tissue oxygen metabolism in patients with septic shock through controlling heart rate. Zhonghua Wei Zhong Bing Ji Jiu Yi Xue. 2015; 27: 759-63.

Xu L, Yu WK, Lin ZL, Tan SJ, Bai XW, Ding K, Li N. Impact of beta-adrenoceptor blockade on systemic inflammation and coagulation disturbances in rats with acute traumatic coagulopathy. Med Sci Monit. 2015; 21: 468-76.

Yang S, Liu Z, Yang W, Zhang G, Hou B, Liu J, Shi Q. Effects of the beta-blockers on cardiac protection and hemodynamics in patients with septic shock: A prospective study. Zhonghua Wei Zhong Bing Ji Jiu Yi Xue. 2014; 26: 714-17.

Zhi Y, Wang K, Wang L. Interpretation of the section of Chinese herb medicine in Chinese guidelines for management of severe sepsis and septic shock 2014. Zhonghua Wei Zhong Bing Ji Jiu Yi Xue. 2015; 27: 429-34. 